\title{
Anticoagulación en COVID-19: ¿qué sabemos hoy y qué falta definirse? Una revisión crítica del Comité Vascular Asoneumocito
}

\author{
Anticoagulation in COVID-19: what do we know \\ today and what remains to be defined? A critical \\ review of the Asoneumocyte Vascular Committee
}

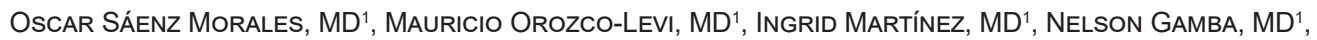
AnA Rubio, MD¹, Julián CoRTez, MD¹, José BLANCo, MD1, AleJandRo Londoño, MD ${ }^{1}$

\section{Introducción}

Desde diciembre del 2019 emergió la infección por coronavirus en el mundo, la cual se declaró pandemia por la Organización Mundial de la Salud (OMS) el 11 de marzo de 2020. Se estableció como epicentro la ciudad de Wuhan, capital de la provincia de Hubei, China (1). Rápidamente se identificó el agente causal de esta enfermedad, un betacoronavirus conocido como síndrome respiratorio agudo severo coronavirus 2 (SARS-CoV-2) (2). Al corte del 05 de junio de 2020, el Centro Europeo para la Prevención y Control de Enfermedades reportaba 6 475644 casos, con 386544 decesos en el mundo (3). Para esta misma fecha, en nuestro país se reportaban 35120 casos y 1087 muertes (4).

\section{Manifestaciones clínicas}

El espectro clínico de la infección ha mostrado ser muy amplio, desde pacientes con síntomas respiratorios leves, semejantes a un catarro, hasta neumonías severas, con hipoxemia marcada refractaria al manejo usual, que lleva a desenlaces mortales. Los síntomas principalmente reportados al inicio de la enfermedad, en frecuencia de presentación, son fiebre $(88,7 \%)$, tos $(67,8 \%)$, fatiga $(38,1 \%)$ y producción de esputo $(33,7 \%)$ (1). Los pacientes con manifestaciones severas de esta infección presentan cuadros de sepsis, choque séptico, falla respiratoria y síndrome de dificultad respiratoria aguda (SDRA), siendo este último uno con los desenlaces de peor pronóstico de la enfermedad, considerado como una de las principales causas de muerte. Su etiología se considera por lesión directa del virus, a nivel alveolar, o indirecta, por un complejo mecanismo inflamatorio, que genera una respuesta desproporcionada a nivel del intersticio pulmonar.

Se ha observado una alta incidencia de fenómenos protrombóticos, como enfermedades tromboembólicas sintomáticas y no sintomáticas, en los pacientes internados en servicios de hospitalización y en unidades de cuidado intensivo (UCI); en este último se ha documentado desde $25 \%$, mientras que otras cohortes hablan
${ }^{1}$ Médico Internista Neumólogo; miembro del Comité de Enfermedad Vascular Pulmonar de la Asociación Colombiana de Neumología.

Autor de correspondencia: Oscar Sáenz Morales, MD.

Correo electrónico: oasm16790@gmail.com

Recibido: 02/07/2020

Aceptado: 15/07/2020 
de $48 \%$ de los pacientes al día $14(5,6)$. Como vemos, en el contexto del paciente crítico, la tasa de presentación de estos eventos es mucho más alta comparado con pacientes sin COVID-19, donde la incidencia oscila entre el 5,4\% y el $29 \%$ en diferentes estudios (7).

Se observan manifestaciones en la micro y macrovasculatura arterial, que se manifiesta como isquemia en extremidades inferiores de diferente grado de severidad, desde acrocianosis, flictenas hasta gangrena seca (Figura 1 y 2) (8). También se ha encontrado aumento de los casos de accidente cerebrovascular (ACV) en pacientes menores de 50 años, con sintomatología respiratoria previa al evento, y con cambios imagenológicos en tomografía de tórax compatibles con la infección y reporte positivo para SARS-CoV-2, sin encontrar otras posibles causas que expliquen estos eventos; se calcula que su incidencia aproximada es cercana al 5,7\% ( 9 , 10). También se muestran hallazgos histopatológicos post mortem, que confirman microtrombosis en la microvasculatura arterial (vasos $<1 \mathrm{~mm}$ ) en la mayoría de las muestras examinadas (Figura 3 y 4) $(11,12)$.
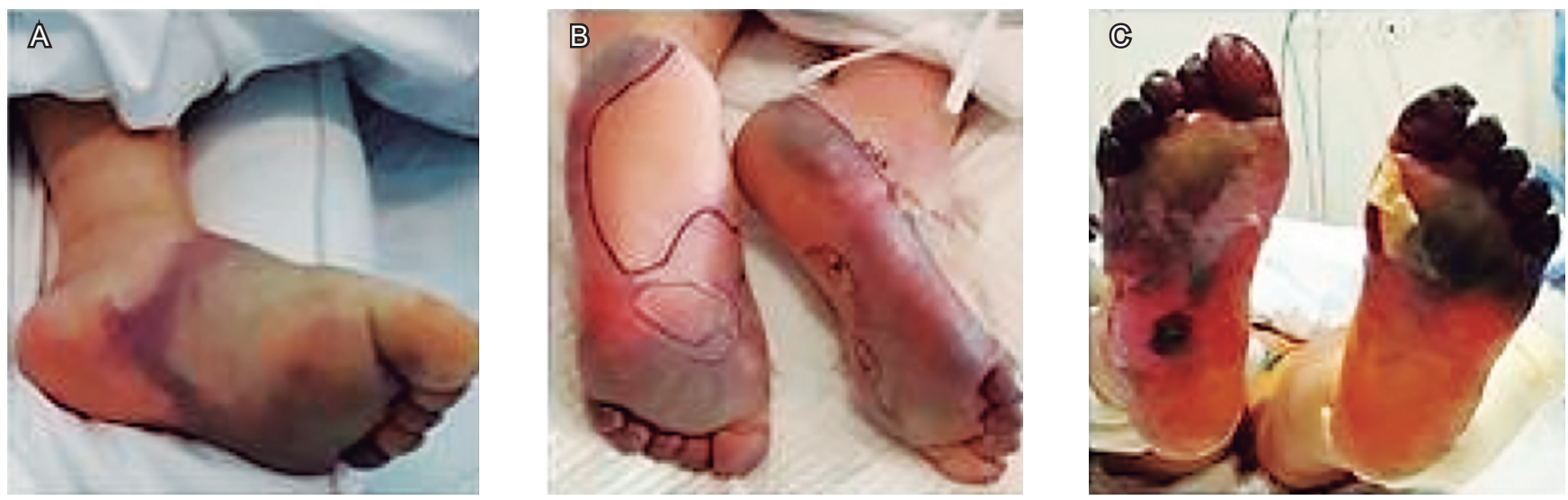

Figura 1. Isquemia critica en extremidades inferiores en pacientes con COVID-19. A. Leucoplasia plantar. B. Flictenas. C. Gangrena seca (8).
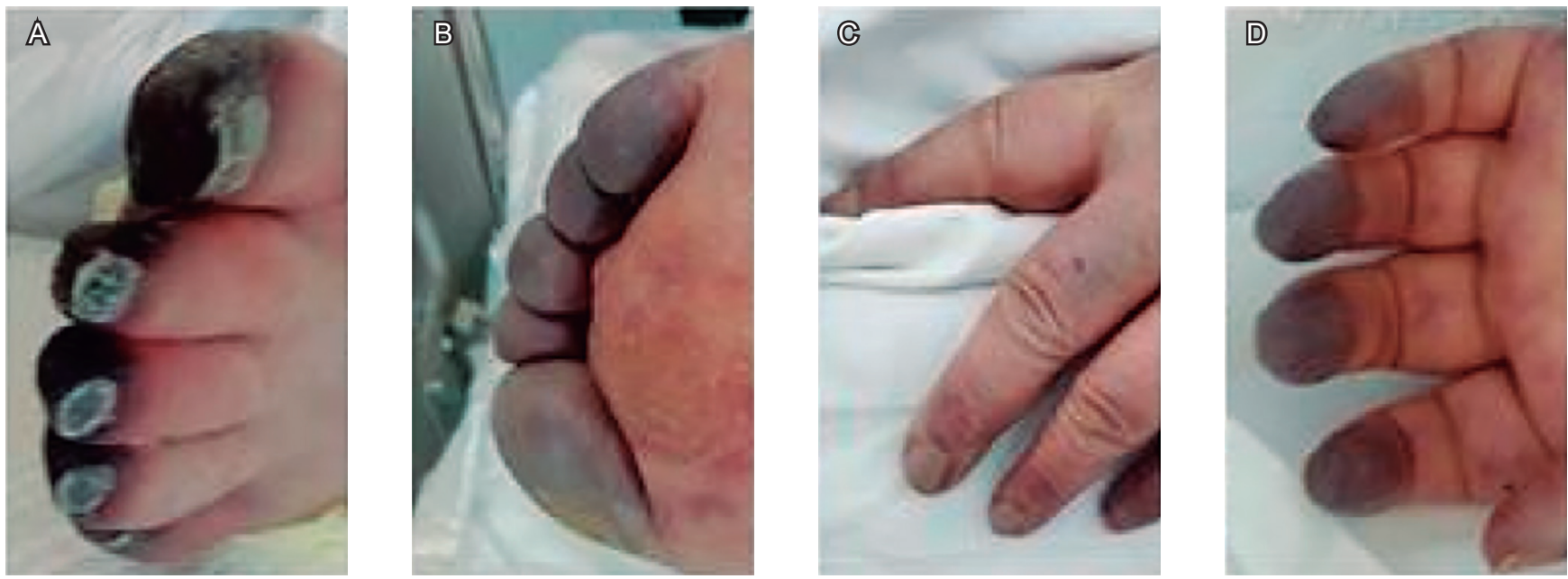

Figura 2. Manifestación isquémica distal en pacientes con infección por COVID-19. Hematomas acrales y gangrena (8). 

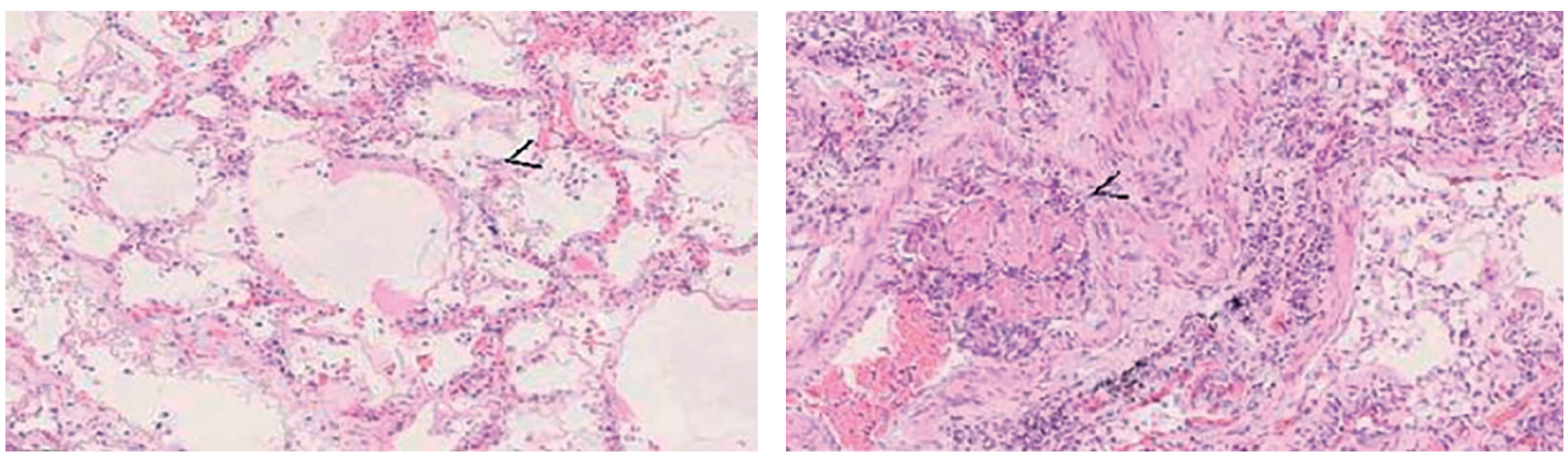

Figura 3. Estudio histopatológico de parénquima pulmonar con daño alveolar difuso en fase exudativa, con membrana hialina y microtrombos organizados, secundario a infección por SARS-CoV-2 (11).
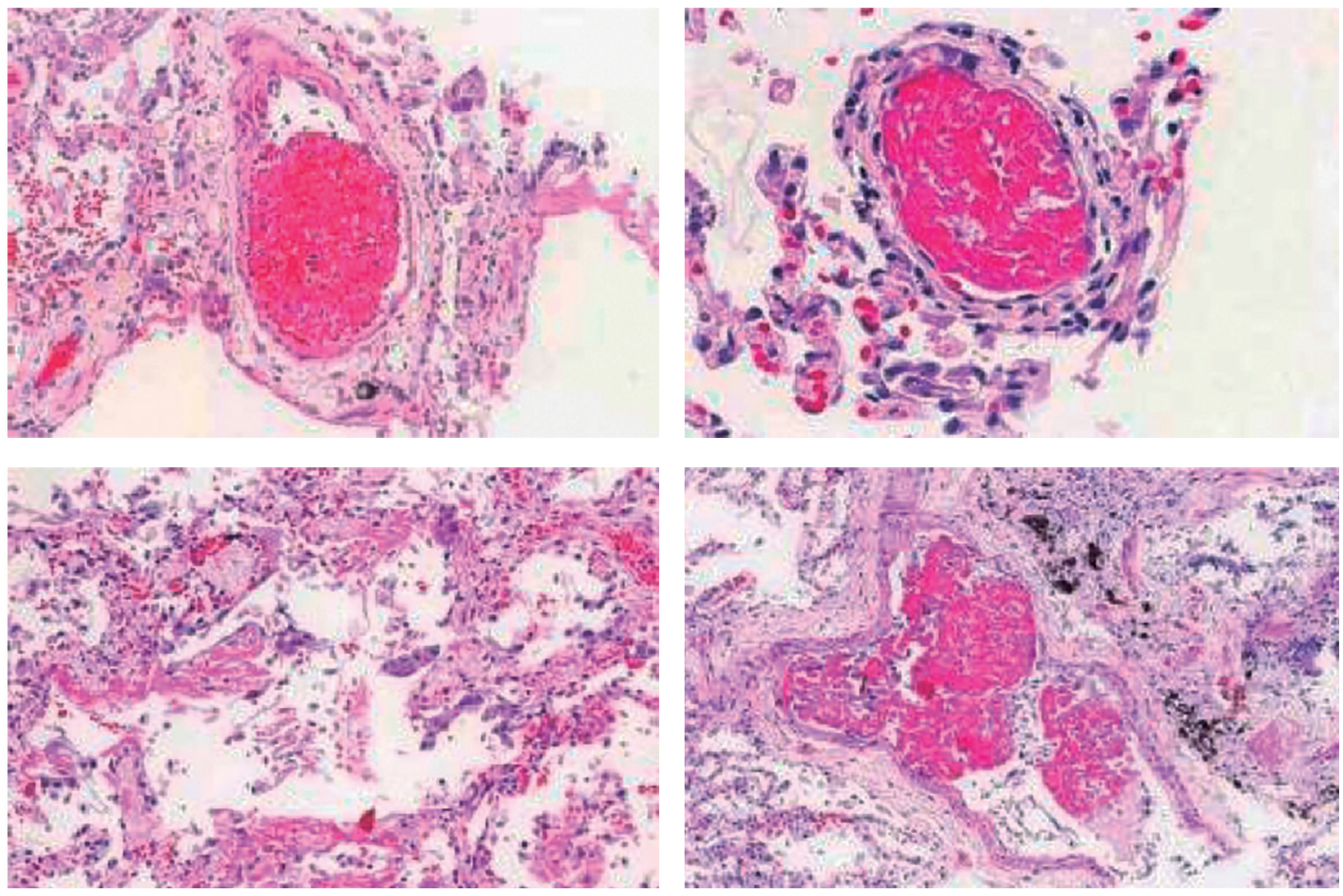

Figura 4. Daño alveolar difuso en COVID-19 mortal, donde se observan microtrombos de fibrina en arteriolas de pequeño tamaño (12). 


\section{Asociación entre la infección por COVID-19 y las alteraciones en la hemostasia}

La disfunción orgánica y las coagulopatías se han asociado con altas tasas de mortalidad (13). En las presentaciones severas de la enfermedad resaltan anomalías de la hemostasia, que llevan al paciente principalmente a un estado de hipercoagulabilidad y, en algunas ocasiones, relacionado con la coagulación intravascular diseminada (CID), pero la coagulopatía asociada con infección por COVID-19 tiene características distintas (14).

La fisiopatología de la CID es compleja y multifactorial (Figura 5). Esta reúne elementos celulares y plasmáticos del sistema hemostásico y de la respuesta inmunológica innata, que promueve la activación del endotelio, plaquetas y leucocitos, cuyo resultado es el desbalance y sobreproducción de trombina a nivel del capilar pulmonar, con aumento de los depósitos de fibrina, daño tisular y microangiopatía trombótica local (15). La combinación de trombocitopenia, tiempo de protrombina (TP) prolongado y aumento del dímero D es sugestivo de CID, aunque el patrón es claramente diferente a la CID observada en la sepsis (16). Sabemos la estrecha relación entre la inmunidad innata y la coagulación, en donde la activación por parte de los patógenos induce la expresión del factor tisular en monocitos y macrófagos. La CID varía de acuerdo con la causa subyacente; en sepsis, la coagulopatía aparece cuando se inhibe la fibrinólisis (17).

Debemos considerar que el espectro de manifestaciones de la CID no solo se remonta a la producción de coágulos de fibrina y a las manifestaciones trombóticas subyacentes, sino que el consumo de plaquetas y de factores de coagulación pueden llevar a los pacientes a manifestaciones hemorrágicas (18). En el caso de los pacientes con COVID-19, vemos que el sistema hemostático se desplaza notablemente hacia el lado procoagulante.

En la sepsis, la trombocitopenia suele ser más profunda, la prolongación del TP es notoria y se observa un descenso más marcado del fibrinógeno; las concentraciones de dímero D no alcanzan los valores tan elevados observados en los pacientes con infección por COVID-19. Sin embargo, en una cohorte, cerca del $71 \%$ de los no sobrevivientes por la infección cumplió con los criterios de CID asintomática ( $>5$ puntos), establecidos por la International Society on Thrombosis and Haemostasis (ISTH). El tiempo medio de instauración de la CID fue de 4 días después de su ingreso; en contraparte, solo $0,6 \%$ de los sobrevivientes cumplía estos criterios (13).

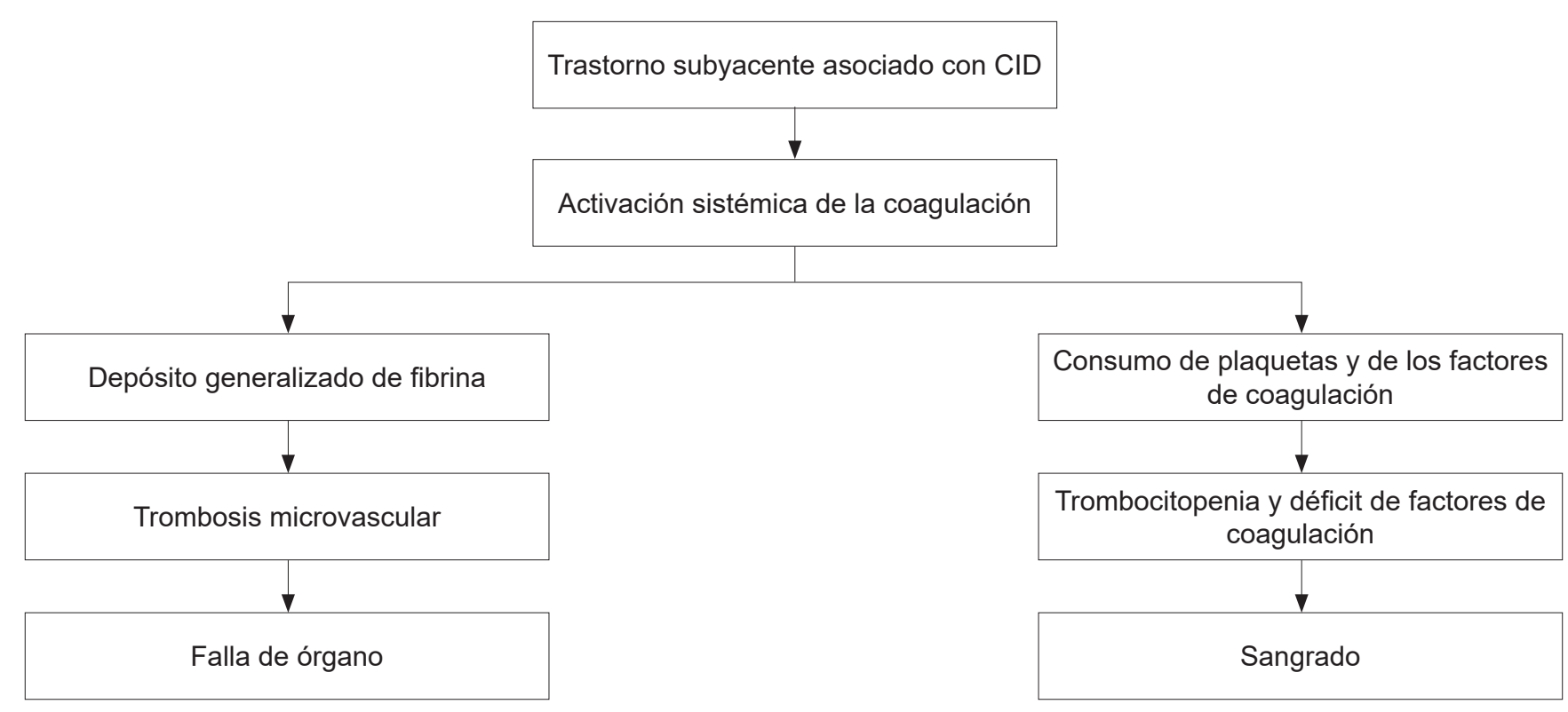

Figura 5. Fisiopatología de la CID (18). 
Algunos estudios reportan el beneficio de la terapia anticoagulante en pacientes con CID asociada con sepsis, y su tendencia es hacia la reducción de la mortalidad en este grupo de pacientes (19). Para el tamizaje se ha usado el puntaje overt DIC, propuesto por la ISTH (DIC Scientific and Standarization Committee [SSC]) en 2001 (20). Sin embargo, en el 2017, la ISTH propuso la escala llamada coagulopatía inducida por sepsis (CIS), dada la necesidad de hacer una detección más precoz de pacientes con CID y ofrecer un beneficio mayor con la terapia anticoagulante (21) (Tabla 1).

Esta escala tiene en cuenta 3 ítems: TP, conteo plaquetario y compromiso orgánico producido por la infección, establecido por el puntaje Sequential Organ Failure Assessment (SOFA), retirando el fibrinógeno y los productos de degradación de la fibrina, que proponía el overt $D I C$, y el fibrinógeno en la escala de la Japanese Association for Acute Medicine Diagnostic Algorithm and Scoring for Disseminated Intravascular Coagulation (JAAM-DIC). Con un puntaje en CIS de 4 puntos se alcanzó una mortalidad cercana al 30\% con 4 puntos, la cual incrementó hasta casi el $45 \%$ en pacientes con 6 puntos a 28 días (22).

Tabla 1. Puntuación para la clasificación de CID y CIS (21)

\begin{tabular}{|c|c|c|c|}
\hline Ítem & Puntaje & $\begin{array}{c}\text { CID } \\
\text { Rango }\end{array}$ & $\begin{array}{c}\text { CIS } \\
\text { Rango }\end{array}$ \\
\hline $\begin{array}{l}\text { Conteo de } \\
\text { plaquetas } \\
\left(-10^{9} / \mathrm{L}\right)\end{array}$ & $\begin{array}{l}2 \\
1\end{array}$ & $\begin{array}{c}<50 \\
\geq 50 ;<100\end{array}$ & $\begin{array}{c}<100 \\
\geq 100 ;<150\end{array}$ \\
\hline \multirow[t]{2}{*}{ Dímero D } & 3 & $\begin{array}{c}\text { Fuerte } \\
\text { incremento }\end{array}$ & - \\
\hline & 2 & $\begin{array}{l}\text { Moderado } \\
\text { incremento }\end{array}$ & - \\
\hline \multirow[t]{2}{*}{ PT (INR) } & 2 & $\geq 6 \mathrm{~s}$ & $(>1,4)$ \\
\hline & 1 & $\geq 3 \mathrm{~s} ;<6 \mathrm{~s}$ & $(>1,2 ; \leq 1,4)$ \\
\hline Fibrinógeno & 1 & $<100$ & - \\
\hline \multirow[t]{2}{*}{ SOFA } & 2 & - & $\geq 2$ \\
\hline & 1 & - & 1 \\
\hline \multicolumn{2}{|c|}{ Puntuación total } & $\geq 5$ & $\geq 4$ \\
\hline
\end{tabular}

\section{Fisiopatología}

Este virus se une a los receptores de la enzima convertidora de angiotensina 2 (ECA 2), por medio de una proteína en forma de pico (S). Dicha proteína permite la fusión de la membrana viral con la membrana de la célula del huésped (23). Al igual que en el caso del virus SARS-CoV, la proteína $S$ comparte una alta afinidad por el mismo receptor de la célula huésped, lo que activa las proteasas del huésped, como las catepsinas, la proteasa transmembrana de la superficie celular proteasa/serina (TMPRSS), la furina, la tripsina, la plasmina y el factor $\mathrm{Xa}$, que facilita la entrada del virus a la célula huésped por medio de la subunidad S2 (24) (Figura 6).

La ECA 2 principalmente se localiza en los neumocitos tipo II, así como en el endotelio arterial y venoso, y en el músculo liso arterial, pero una mayor concentración se encuentra en las células epiteliales alveolares a nivel pulmonar y en las células de enterocitos del intestino delgado, que están en contacto con el ambiente externo, lo que permite su entrada al huésped (25, 26). Esta afinidad ha demostrado ser 10 a 20 veces mayor en comparación con la afinidad vista con el virus SARS-CoV (23).

LA ECA 2 tiene un papel en la regulación de la inmunidad innata, que sugiere que la regulación a la baja, por su unión, internación y ulterior inhibición mediada de forma inmunológica, podría incrementar el riesgo de inmunotrombosis en los humanos. Esta enzima tiene un papel contrarregulador importante en el sistema renina angiotensina aldosterona (SRAA), en el que se degrada la angiotensina II a angiotensina, esto disminuye sus efectos vasoconstrictivos y profibróticos, y la retención de sodio.

A pesar de su parecido estructural con la ECA, sus sitios activos son distintos, y no hay datos concluyentes de que sus niveles aumenten en pacientes que son tratados con inhibidores de la enzima convertidora de angiotensina (IECA) o antagonistas del receptor de angiotensina II (ARA II), pero se debe tener en consideración que el desbalance en el SRAA y el aumento de la actividad de la angiotensina II, así como sus efectos cardiolesivos, pueden afectar principalmente a los pacientes con enfermedad cardiovascular subyacente, donde se ha encontrado que el COVID-19 presenta manifestaciones particularmente severas, y en donde la suspensión de medicamentos que inhiben el SRAA (IECA o ARA II) puede emporar los desenlaces clí- 
nicos $(27,28)$. Asimismo, no hay evidencia suficiente para afirmar que las personas que ya reciben estos medicamentos tengan un riesgo mayor de contraer la enfermedad (29).

Las interleucinas (IL) 1 e IL-6, y el factor de necrosis tumoral (TNF), se ven involucradas en la inmunopatogenia de los eventos trombóticos, dado que estas interleucinas actúan a nivel del endotelio celular, al activar la cascada de la coagulación, por medio del factor tisular, lo que genera una reacción en cadena, que lleva a la producción aumentada de trombina. La IL-6 puede inducir la expresión del factor tisular en las células mononucleares, lo que luego inicia la activación de la coagulación y la generación de trombina. EL TNF- $\alpha$ e IL-1 son los principales mediadores que impulsan la supresión de las vías anticoagulantes endógenas.

En este nivel, la estrategia de tratamiento debe ser el bloqueo del estado hipercoagulable con anticoagulantes tipo heparina de bajo peso molecular (HBPM) para bloquear la trombina y amortiguar la respuesta inflamatoria (30). Otras citocinas proinflamatorias (IL2, IL-7, factor estimulador de colonias granulocíticas, la proteína 10 inducida por interferón gamma [IP 10], MCP-1, MIP1A y TNF- $\alpha$ ) se han observado en pacientes admitidos a unidades de cuidado crítico con $\mathrm{CO}$ VID-19 (31).

La disfunción endotelial lleva a un estado procoagulable, a vasoconstricción y a inflamación local. Se ha encontrado acumulación de células inflamatorias y cuerpos de apoptosis en el endotelio del corazón, intestino delgado y pulmón. Es así como la endotelitis ha sido parte del desarrollo de eventos isquémicos en el intestino, el hígado y el corazón, por daño directo del virus, así como por inflamación endotelial difusa (32).

El compromiso pulmonar visto en los pacientes afectados por esta entidad muestra unas características muy importantes, en las que se destaca la presencia marcada de trombosis y hemorragia microvascular, asociadas con afectación alveolar y una respuesta inflamatoria desproporcionada en el intersticio. La liberación de citocinas parece afectar a los pacientes con condiciones severas, lo que perpetúa el daño a este nivel (33). La trombosis pulmonar desencadenada por el virus puede ser una causa muy importante en el desenlace de esta enfermedad, más que la infección propiamente dicha. Se considera que la estrecha relación anatómica de los neumocitos tipo II y la vasculatura pulmonar, en un entorno caracterizado por una respuesta inflamatoria francamente aumentada, facilita un estado hipercoagulable. Este puede ser la causa de muerte de estos pacientes, y uno de los puntos críticos donde las intervenciones terapéuticas tempranas pueden mejorar el pronóstico de esos pacientes (34) (Figura 7).

La afectación a este nivel, dada por la respuesta inmunológica local, conlleva a una disminución de la oxigenación, que a su vez activa las vías de señalización, lo que favorece la producción de factores promotores de trombosis, como el factor inhibidor del activador de plasminógeno 1 , mediado por el factor de transcripción inducible por hipoxia (HIF) (35). Al establecer un círculo vicioso, que aumenta la producción de trombosis a este nivel, el HIF no solo estimula los factores protrombóticos, sino también la producción de mediadores proinflamatorios, como el TNF, la IL-1, la respuesta de crecimiento temprana 1 (EGR 1), que regula la formación del trombo, y los factores antitrombóticos, los cuales pueden predisponer a microhemorragias (34) (Figura 8).

La disminución de la actividad del interferón tipo 1 es otra de las hipótesis que se maneja, que puede estar relacionada con un estado hipercoagulable. Se cree que esta disminución de la activación de este interferón, que se observa con el aumento de la edad, se ha asociado con respuestas inmunes innatas desproporcionadas, asociadas con la activación de la vía $\mathrm{NF}$ kB, así como con la elevación de IL-8 y con la expresión del factor tisular que, como se mencionó, activa la vía extrínseca de la cascada de la coagulación (34).

\section{Hallazgos paraclínicos}

Tang y colaboradores describieron el comportamiento de la coagulación en pacientes con neumonía por coronavirus. Los autores observaron valores significativamente altos de dímero $\mathrm{D}$ y productos de degradación de la fibrina, disminución relativamente modesta en el recuento de plaquetas y prolongación de los tiempos de coagulación (13). 


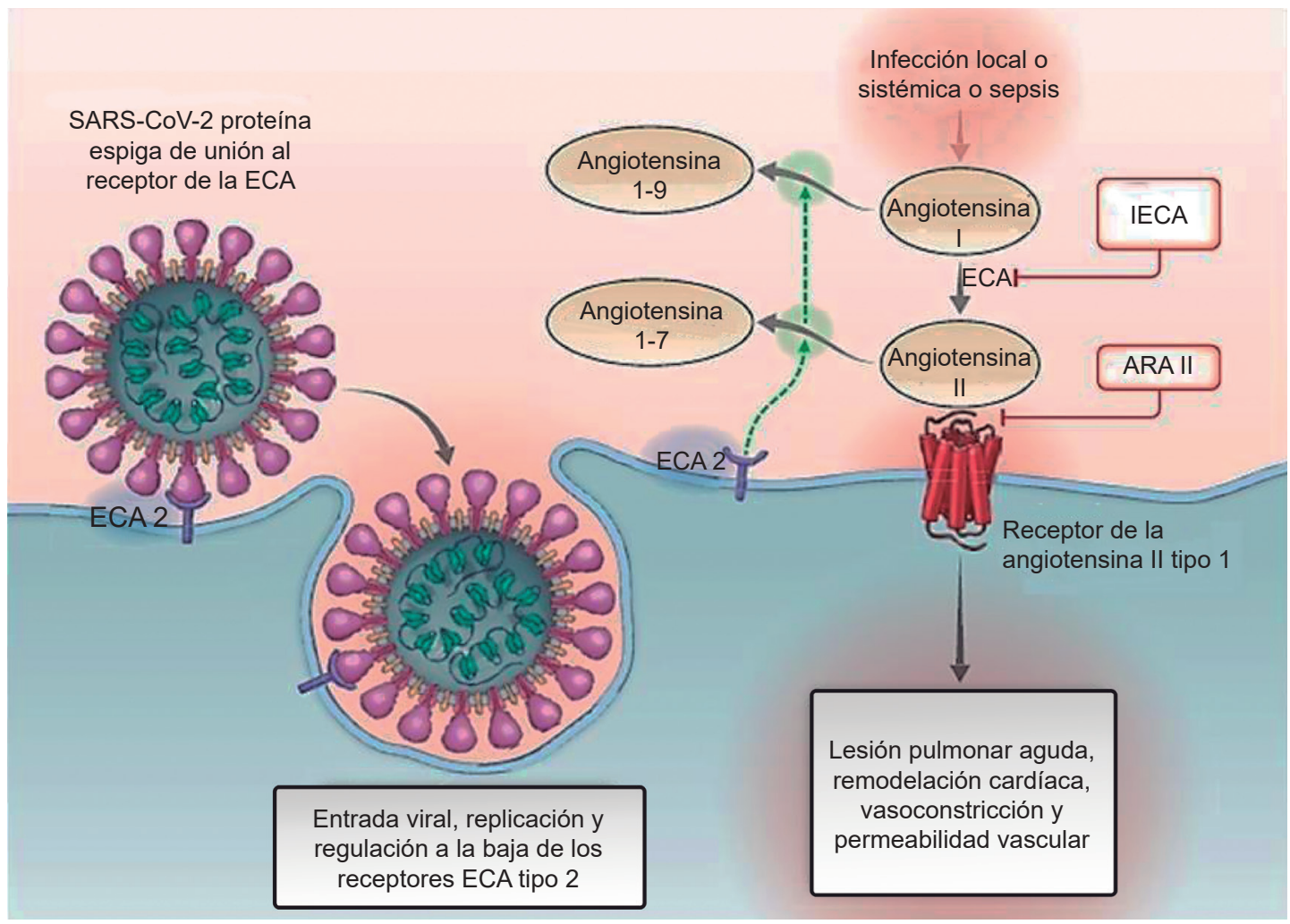

Figura 6. Mecanismo de ingreso a la célula del virus por medio del receptor ECA 2, lo que favorece la endocitosis del virus y la regulación a la baja, y aumenta las concentraciones de angiotensina II y sus efectos cardiolesivos (28).

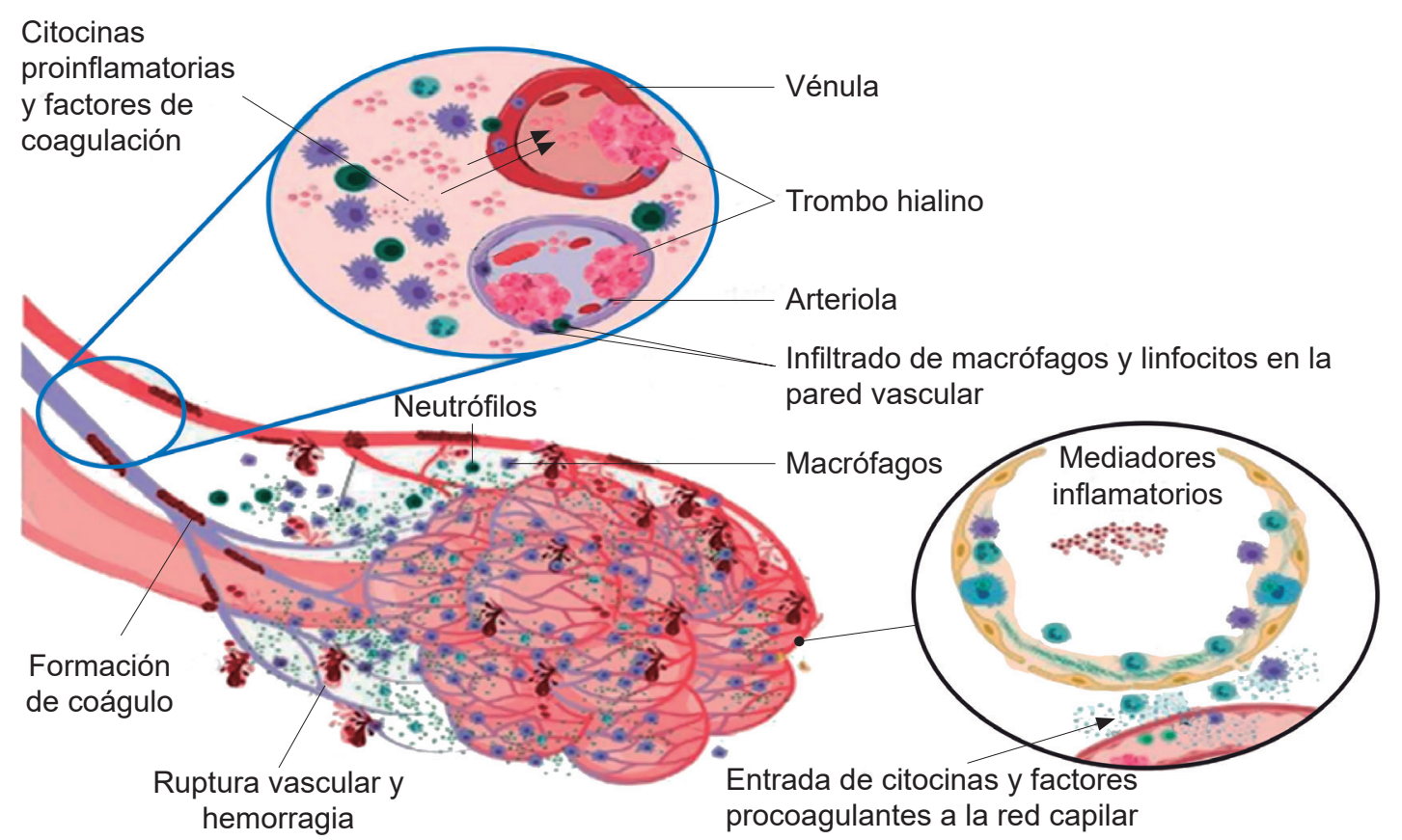

Figura 7. Imagen que demuestra el compromiso pulmonar mediado por citocinas proinflamatorias y factores procoagulantes en el intersticio y en la superficie de los neumocitos tipo II, lo que causa microtrombos inmunomediados. Se observa un extenso reclutamiento de macrófagos en el intersticio, similar al cuadro clínico del síndrome de activación de macrófagos. Asimismo, se observa el acceso a la red capilar de estos mediadores inflamatorios y factores procoagulantes (34). 


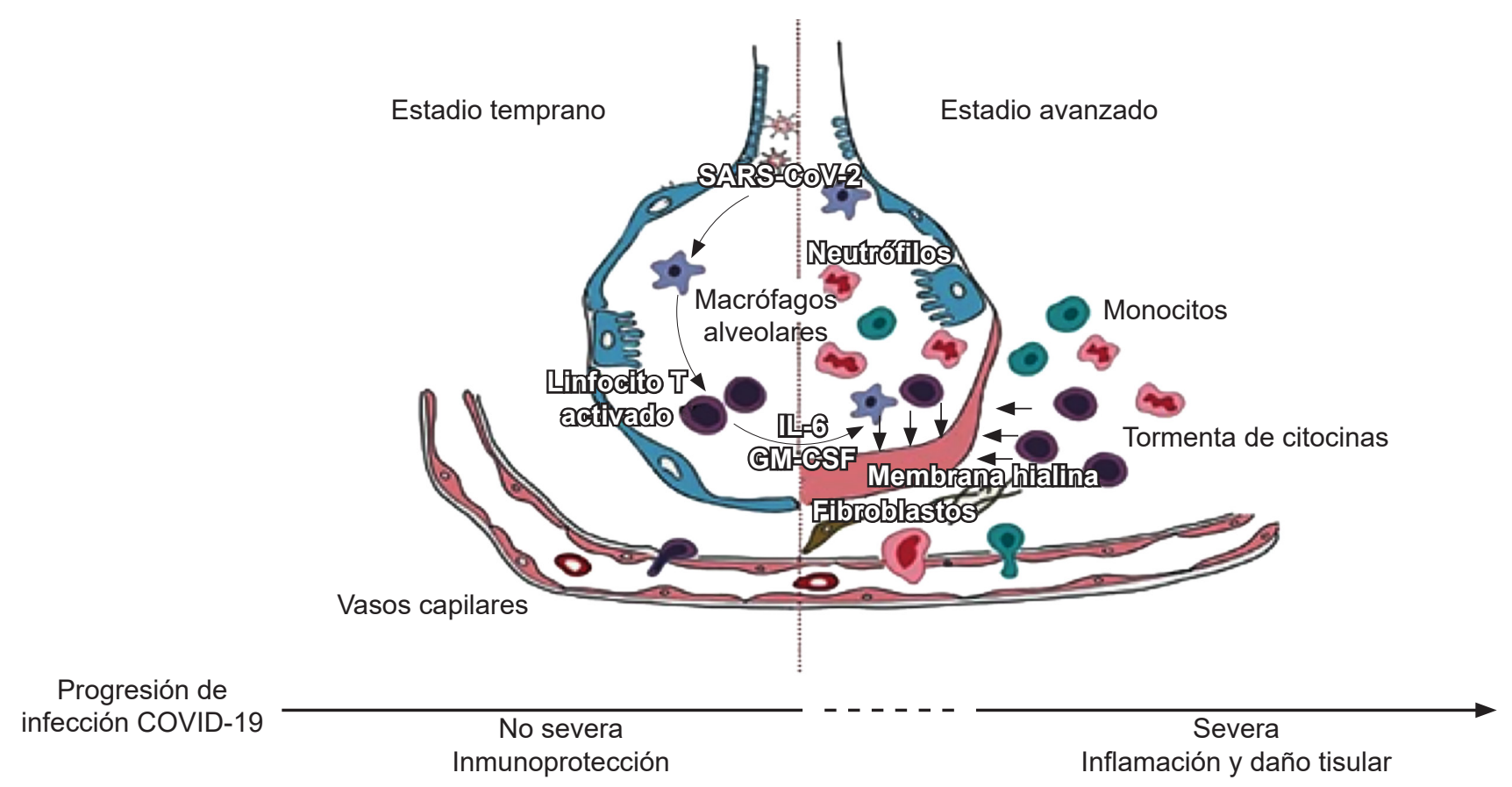

Figura 8. Respuesta inmunológica exagerada en el intersticio alveolocapilar, secundaria a la tormenta de citocinas (33).

Los factores que confieren un alto riesgo de desenlaces desfavorables son la presencia de linfopenia, ferritina elevada, lactato deshidrogenasa (LDH) elevado, albúmina baja y condiciones clínicas, como lo es una edad mayor de 60 años, severidad de la enfermedad al ingreso, establecida por la escala de SOFA mayor de 2 puntos, y comorbilidades concomitantes. Entre los anteriores resalta el dímero $\mathrm{D}$, y se encuentran valores elevados en pacientes que requirieron manejo en unidad de cuidado crítico comparado con aquellos que no $(2,4 \mathrm{mg} / \mathrm{L}$ frente a $0,5 \mathrm{mg} / \mathrm{L})$, y valores $>1 \mu \mathrm{g} / \mathrm{mL}$ en el $81 \%$ de los no sobrevivientes en esta cohorte de pacientes, con un OR de 18,42 y $p=0,0033(31,36)$. Los valores mayores de $1,5 \mu \mathrm{g} / \mathrm{mL}$ se asociaron con mayor riesgo de presentar fenómenos tromboembólicos, con una sensibilidad del $85 \%$, especificidad de $88,5 \%$, valor predictivo positivo de $70,5 \%$ y un valor predictivo negativo de $94,7 \%$, también estuvo elevado en los casos con complicaciones arteriales $(5,8)$.

El dímero $\mathrm{D}$ es un producto de degradación de la fibrina, y su formación está mediada principalmente por tres enzimas: la trombina, el factor XIIIa y la plas- mina. Normalmente, los productos de degradación de la fibrina (complejo E-dímero D) no son detectados en la circulación, sin embargo, fragmentos moleculares solubles de alto peso molecular que contienen dímero D están presentes en la CID y otras alteraciones trombóticas (37) (Figura 9).

Asimismo, es importante resaltar que los valores de dímero D incrementan con la edad. En adultos mayores de 60 años, inicialmente los valores superan los $500 \mathrm{ng} / \mathrm{mL}$, y después de los 80 , menos del $5 \%$ tiene un valor de dímero D negativo (38). En cuanto a las diferentes técnicas para medir el dímero $\mathrm{D}$, aquellas con mayor sensibilidad son la prueba de Enzime-Linked Immunosorbent Assay (ELISA) y la prueba rápida cualitativa ELISA sobre otro tipo de pruebas (aglutinación por látex cuantitativa, semicuantitativa, entre otras). El valor predictivo negativo de esta prueba tiene tasas similares a estudios escenográficos normales o casi normales, así como a hallazgos negativos de Doppler de miembros inferiores en pacientes con sospecha de embolia pulmonar (EP) y trombosis venosa profunda (TVP) (39). 


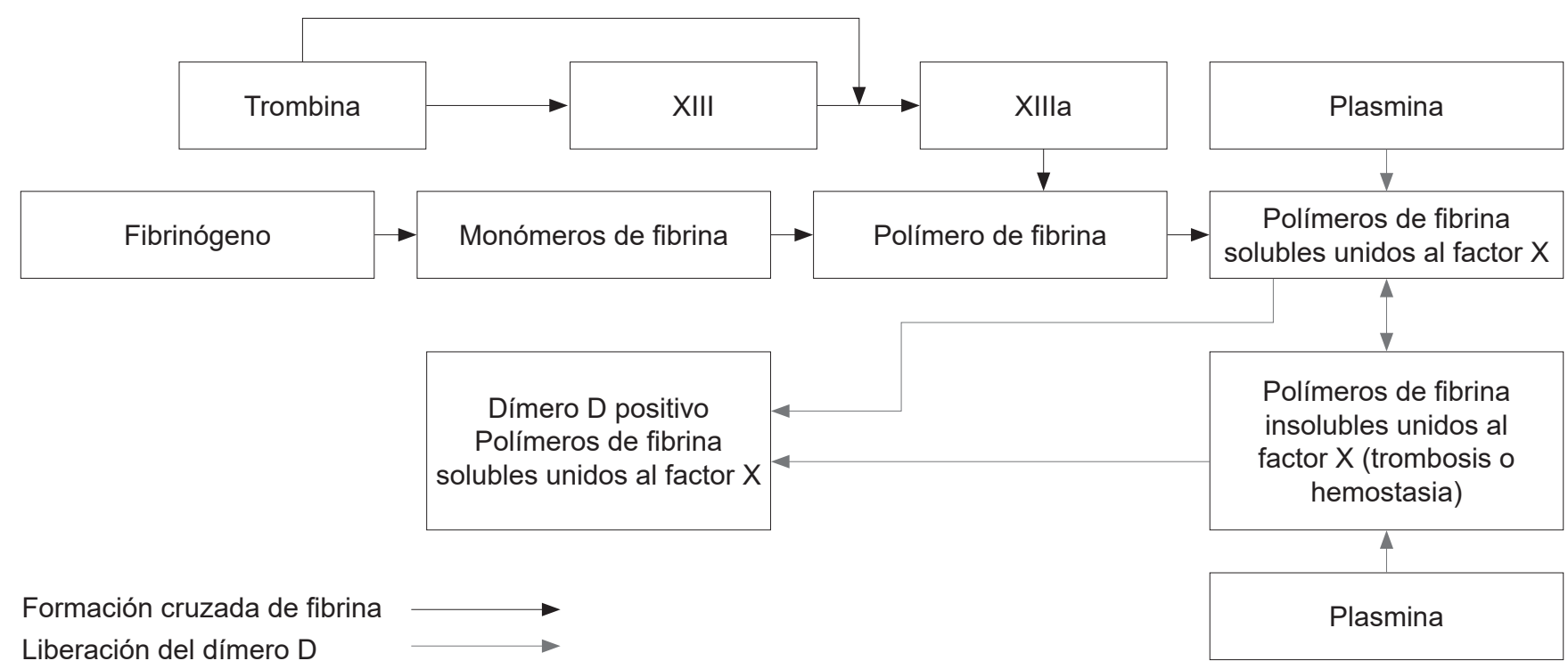

Figura 9. Formación del dímero D. Primero, la trombina se adhiere al fibrinógeno, lo que produce monómeros de fibrina. Se presenta activación del factor XIII, por medio de la trombina, este favorece la unión covalente entre los dominios $\mathrm{D}$ y la fibrina polimerizada. Por último, la plasmina rompe esta unión, lo que libera los productos de degradación de la fibrina y el dímero D (37).

El fibrinógeno es otro estudio paraclínico que se encontró alterado en los pacientes con COVID-19. Los valores disminuidos nos orientan a pensar que el paciente está con CID. Paradójicamente, en los pacientes con COVID-19, este parámetro tiene la tendencia a estar elevado, presumiblemente como una respuesta de fase aguda; sin embargo, se observó una disminución repentina en el fibrinógeno plasmático, en concentraciones inferiores a $1 \mathrm{~g} / \mathrm{L}$, poco antes de la muerte en varios pacientes en China (14).

Valores elevados de troponina también se han asociado con peores desenlaces en pacientes con o sin antecedentes de enfermedad cardiovascular. A su vez, se relaciona con mayor presencia de coagulopatía, encontrándose mayor prolongación del TP, acortamiento de los valores de tromboplastina y valores significativamente altos de dímero $\mathrm{D}$ (27).

Se ha investigado sobre otras herramientas que le puedan ser útil al clínico para detectar precozmente esta coagulopatía. El uso de la tromboelastografía, que nos permite tener una visión más completa de la coagulación, evalúa la contribución de las plaquetas en la formación y resistencia del coágulo, que no se consi- dera en la evaluación de rutina de la coagulación (TP y tiempo parcial de tromboplastina activado [aPTT]), y es de suma importancia en el paciente críticamente enfermo (40). Esta se volvió popular en los últimos años para la monitorización y manejo transfusional en cirugía mayor, trauma y hemofilia (41).

Panigada y colaboradores realizaron un estudio de tromboelastografía en 24 pacientes admitidos a la unidad de cuidado crítico. Se encontraron hallazgos consistentes con el estado de hipercoagulabilidad. Se observó una disminución de los valores de R y K, y un incremento de los valores del ángulo K y MA, hallazgos que discrepan de las características de los pacientes con CID secundaria a sepsis, pero que soportan un estado de hipercoagulabilidad asociado con un estado inflamatorio severo (42) (Figura 10).

\section{Monitorización de la coagulopatía}

La hipercoagulabilidad es un problema importante en pacientes con infección por COVID-19, el sistema hemostático se desplaza notablemente hacia el lado procoagulante en estos pacientes. Dada las características protrombóticas de estos pacientes, la ISTH propone 
que se debe hacer un seguimiento estricto de los parámetros paraclínicos que puedan alarmar al médico, de forma temprana, de que el paciente está desarrollando CID. El reconocimiento anticipado lleva a establecer medidas oportunas y consecuentes, con el fin de disminuir la mortalidad de esta entidad. La monitorización del dímero $\mathrm{D}$ desde el ingreso es una herramienta muy útil para saber cómo se está afectando la hemostasia por la infección. Debemos tener en cuenta que a mayor edad y número de comorbilidades, el dímero $\mathrm{D}$ tenderá a valores más elevados, comparados con personas jóvenes sin preexistencias, a su vez, asociado con un aumento de la mortalidad en estos pacientes, como se mencionó previamente (43).

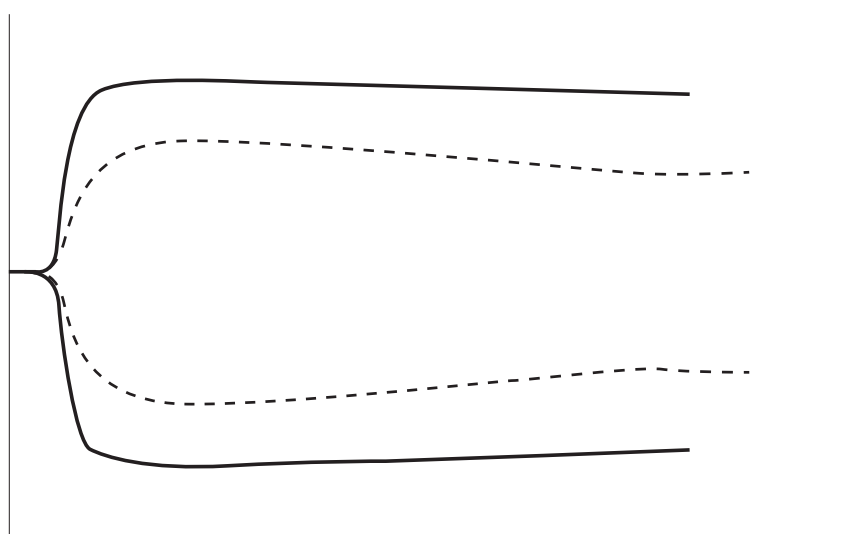

Figura 10. Las líneas de trazo representan los controles, mientras que las líneas continuas muestran a los pacientes con COVID-19 ( $\mathrm{R}=5,5 \mathrm{~min} ; \mathrm{K}=0,9 \mathrm{~min}$; ángulo $\mathrm{K}$ : $78,8^{\circ}$; $\mathrm{MA}=88,8 \mathrm{~mm})(42)$.

Los otros estudios que se deben evaluar cuidadosamente son el TP, el PTT y el conteo plaquetario, dado su alto valor en cuanto a la toma de decisiones orientada por la escala CIS. Otros, como el fibrinógeno y los productos de degradación de la fibrina, nos pueden orientar sobre el grado de coagulación, consumo y activación hemostásico del paciente (18). Usando la evidencia disponible sugerimos monitorizar estos parámetros cada 48-72 horas. Consideramos que el seguimiento de estos parámetros de forma sistemática y de rutina debe tomarse como una herramienta fundamental para orientar la terapéutica de estos pacientes, en pro de medidas más agresivas en los pacientes que presentan empeoramiento de estos paraclínicos y evoluciones tórpidas o no satisfactorias en el entorno hospitalario y de cuidado crítico.

\section{Tratamiento}

Se ha demostrado que en la infección por virus SARS-CoV-2 (COVID-19), la coagulopatía severa se asocia con una alta mortalidad, que se evidencia principalmente por el incremento de los niveles de dímero $\mathrm{D}$ en estos pacientes, el cual es un marcador particularmente importante para este tipo especial de coagulopatía. En pacientes críticamente enfermos, la tromboprofilaxis con HBPM ha demostrado reducir el riesgo de eventos tromboembólicos, sin aumentar el riesgo de sangrado (44).

En el estudio realizado por Tang y colaboradores se demostró que el uso de la heparina puede impactar en la mortalidad de pacientes con infección severa por COVID-19. Se observó una reducción del 24,2\% y del $19,6 \%$ en la mortalidad a 28 días en pacientes quienes cumplían con los criterios CIS $>4$ o dímero $\mathrm{D}>6$ veces el valor normal; CIS $\geq 4$ (40,0\% frente a $64,2 \%$; $P=0,029)$ en pacientes tratados con heparina frente a aquellos que no, respectivamente; el caso del dímero $\mathrm{D}$ elevado fue de $32,8 \%$ frente a $52,4 \% ; P=0,017$ ) (45). Es de resaltar que el principal medicamento utilizado en este estudio fue la HBPM, en dosis de tromboprofilaxis (40-60 mg SC día).

La Sociedad Europea de Radiología y de Imágenes Torácicas sugiere el uso de la angiotomografía para descartar el embolismo pulmonar en pacientes con requerimiento de oxígeno, con una extensión de la enfermedad limitada, así como realizársela inmediatamente si los hallazgos tomográficos no explican la severidad de la falla respiratoria. Bompard y colaboradores reportaron 137 pacientes, a quienes se les realizaron angiotomografías de tórax. El 53\% de este grupo fue de pacientes hospitalizados, todos ellos recibiendo tromboprofilaxis con enoxaparina $40 \mathrm{mg}$ SC día. Se les realizó el estudio imagenológico por deterioro clínico y aumento de los parámetros ventilatorios (en pacientes en la unidad de cuidado crítico), y se encontró una tasa de $24 \%$ de embolismo pulmonar, $50 \%$ en el subgrupo de UCI, de forma llamativa, sin conferir un aumento significativo de la mortalidad en este grupo de pacientes con respecto al total de estudiados (13\% frente a 12\%) (46).

La recomendación actual por la ISTH es de profilaxis tromboembólica a todos los pacientes que requieren 
hospitalización, a menos que exista contraindicación (sangrado activo o plaquetas $<25000$ ). Se recomienda HBPM sobre heparina no fraccionada (HNF), a menos que exista alto riesgo de sangrado, fondaparinux, en el marco de una trombocitopenia inducida por heparina, aunque no está claro si este medicamento tiene los beneficios antiinflamatorios postulados de la heparina. En caso de contraindicación para el uso de anticoagulantes se deberá usar tromboprofilaxis mecánica (47). El consenso chino recomienda iniciar anticoagulación con HNF o HBPM en pacientes con COVID-19 severo y disfunción de la coagulación, definida como overt DIC >5 puntos o Chinese DIC scoring system (CDSS) $>7$ puntos hasta que el dímero $\mathrm{D}$ retorne a sus valores normales. Se deben monitorizar las dosis de acuerdo con los niveles de actividad antiXa, con un objetivo entre 0,6-1 UI/mL para mantener los niveles de la actividad de la antitrombina III (ATIII) por encima del $80 \%$ (48) (Figura 11).

En los pacientes que ya vienen recibiendo anticoagulación oral con antagonistas de vitamina (AVK) o anticoagulantes orales directos, que requieran manejo intramural, tomando en consideración las interacciones farmacológicas de estos medicamentos, inclusive con tratamiento para esta infección, la vida media y características farmacocinéticas, cambios en la dieta, disfunción hepática o renal y la posibilidad de requerimiento de intervenciones urgentes, se recomienda reemplazar los anticoagulantes orales por heparina parenteral, con la excepción de los pacientes con válvulas cardíacas mecánicas o biológicas recientes, en donde los AVK siguen siendo el medicamento de elección, a menos que mantener esta terapia confiera mayores riesgos para el paciente (49).

La Sociedad Española de Trombosis y Hemostasia recomienda administrar tromboprofilaxis a todos los pacientes hospitalizados sin factores de riesgo, con dosis ajustada al peso del paciente y la función renal, y recomiendan dosis mayores, por ejemplo, enoxaparina $1 \mathrm{mg} / \mathrm{kg} /$ día o $0,5 \mathrm{mg} / \mathrm{kg} /$ día con $\mathrm{TFG}<30 \mathrm{~mL} / \mathrm{min}$, si los pacientes presentan uno o más factores de riesgo de trombosis (COVID-19 severo y PCR $>150 \mathrm{mg} / \mathrm{dL}$, dímero $\mathrm{D}>1500 \mathrm{ng} / \mathrm{mL}$, ferritina $>1000 \mathrm{ng} / \mathrm{mL}$, linfopenia $<800 \times 106 / \mathrm{L}, \mathrm{IL}-6>40 \mathrm{pg} / \mathrm{mL}$, o en pacientes que no cumplen los criterios para COVID-19 severo y

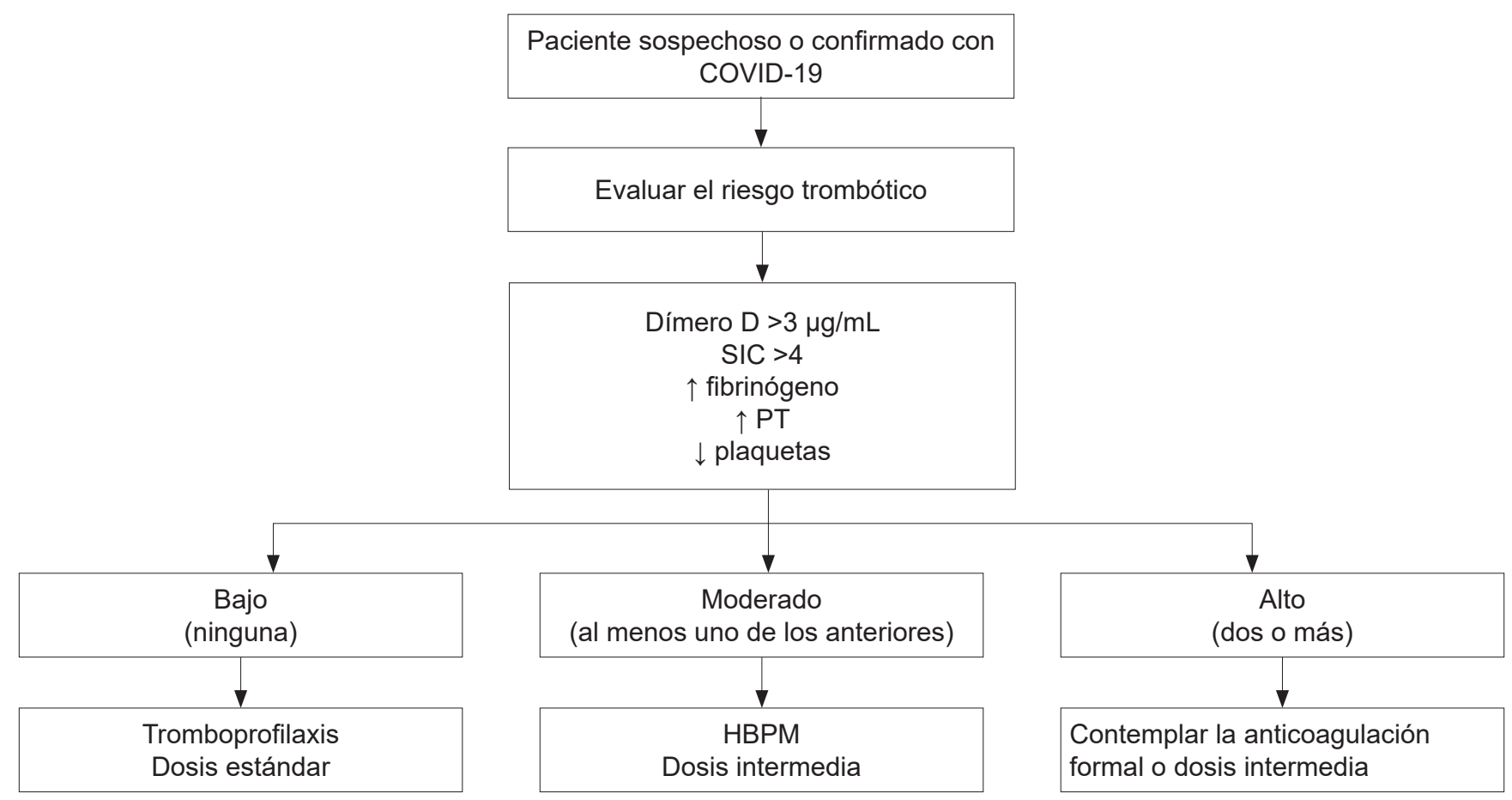

Figura 11. Tromboprofilaxis de acuerdo con el riesgo trombótico. 
dímero $\mathrm{D}>3000 \mathrm{ng} / \mathrm{mL}$, antecedentes personal o familiar de enfermedad trombótica venosa, trombofilia, cirugía reciente, gestación o terapia hormonal) (50).

Con base en lo anterior, en el abordaje terapéutico de los pacientes con COVID-19 consideramos que toma un papel importante la anticoagulación, sin embargo, aun sin evidencia, por la ausencia de estudios que comparen una estrategia de anticoagulación frente a la tromboprofilaxis en los pacientes con alto riesgo de desarrollo de eventos trombóticos, sin poder documentar un evento tromboembólico, se debe realizar una evaluación sistemática de estratificación de riesgo a todos los pacientes con sospecha o casos confirmados de infección desde el ingreso, y durante su estancia hospitalaria, en sala general o en la unidad de cuidado crítico. Cuando se presente evolución tórpida, refractaria al manejo convencional, se deben descartar complicaciones asociadas, como la embolia pulmonar, y contemplar la posibilidad de iniciar precozmente la HBPM en dosis de anticoagulación, aun en casos en que no se haya confirmado un evento tromboembólico subyacente (Figura 12).

Dado lo anterior, se plantea el siguiente algoritmo terapéutico, donde en pacientes con bajo riesgo trombótico se recomienda una dosis estándar de HBPM, de acuerdo con el peso; pacientes con riesgo moderado, que para nosotros se considera cualquier paciente con o sin antecedentes que aumenten el riesgo trombótico y al menos uno de los laboratorios de perfil de hemostasia alterado, se benefician de HBPM en dosis intermedias; y pacientes con 2 o más de estos marcadores alterados se sugiere monitorizar, de acuerdo con el riesgo de sangrado que presente el paciente al inicio de anticoagulación formal.

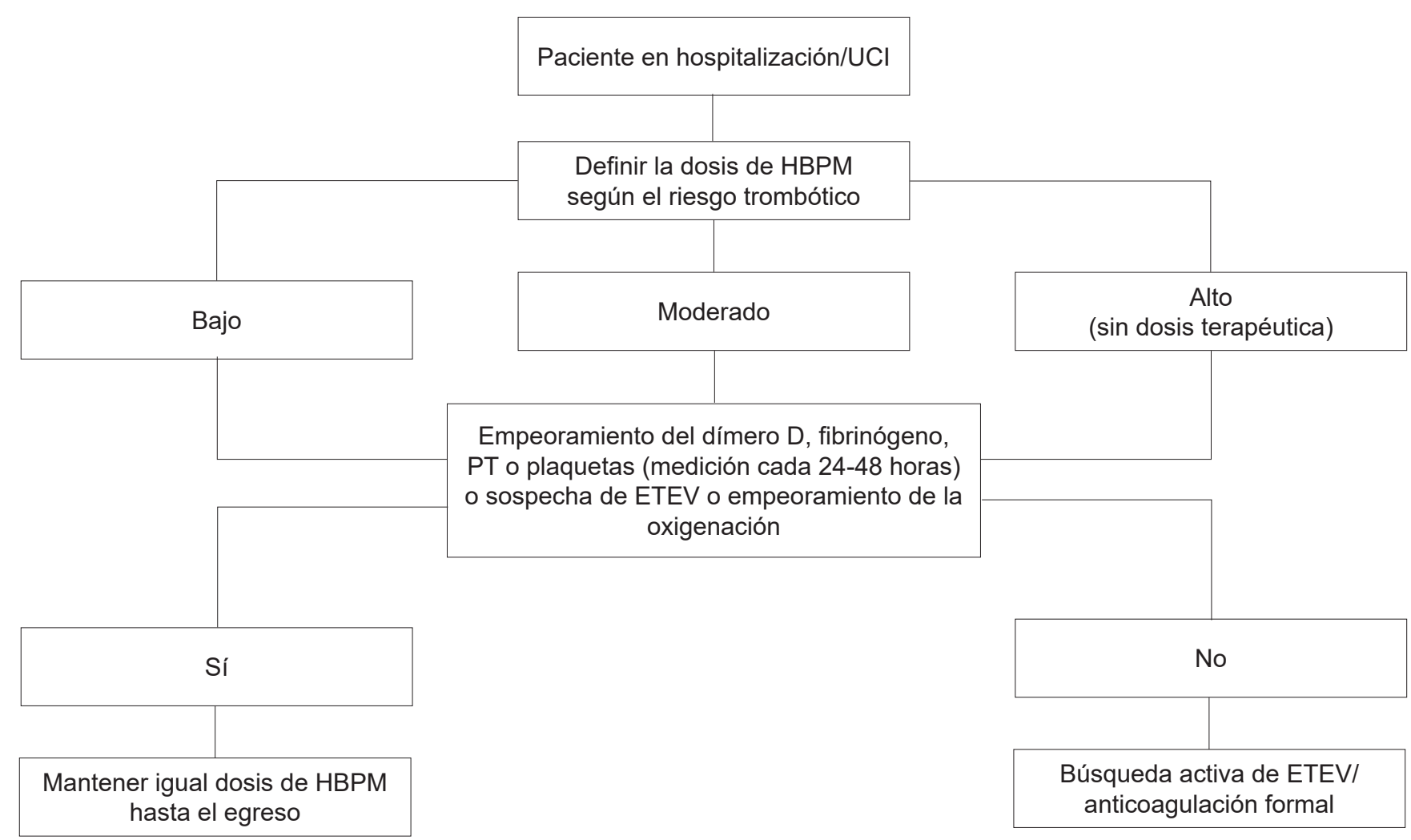

Figura 12. Monitorización de parámetros de coagulación y propuesta de conducta terapéutica, según sea el caso. HBPM: heparina de bajo peso molecular; ETEV: enfermedad tromboembólica venosa; UCI: unidad de cuidados intensivos. 
Tabla 2. Dosis de enoxaparina

\section{Dosis HBPM}

- Dosis profiláctica: $<80 \mathrm{~kg}: 40 \mathrm{mg} / 24$ horas

- >80 kg: $60 \mathrm{mg} / 24$ horas

- Dosis intermedia: $1 \mathrm{mg} / \mathrm{kg}$ cada 24 horas o $0,5 \mathrm{mg} / \mathrm{kg}$ cada 12 horas

- Dosis terapéutica: $1 \mathrm{mg} / \mathrm{kg}$ cada 12 horas o $1,5 \mathrm{mg} /$ $\mathrm{kg} / \mathrm{día}$

- Si TFG $<30 \mathrm{~mL}$ considere reducir la dosis $50 \%$; uso de HNF; medir los niveles antiXa

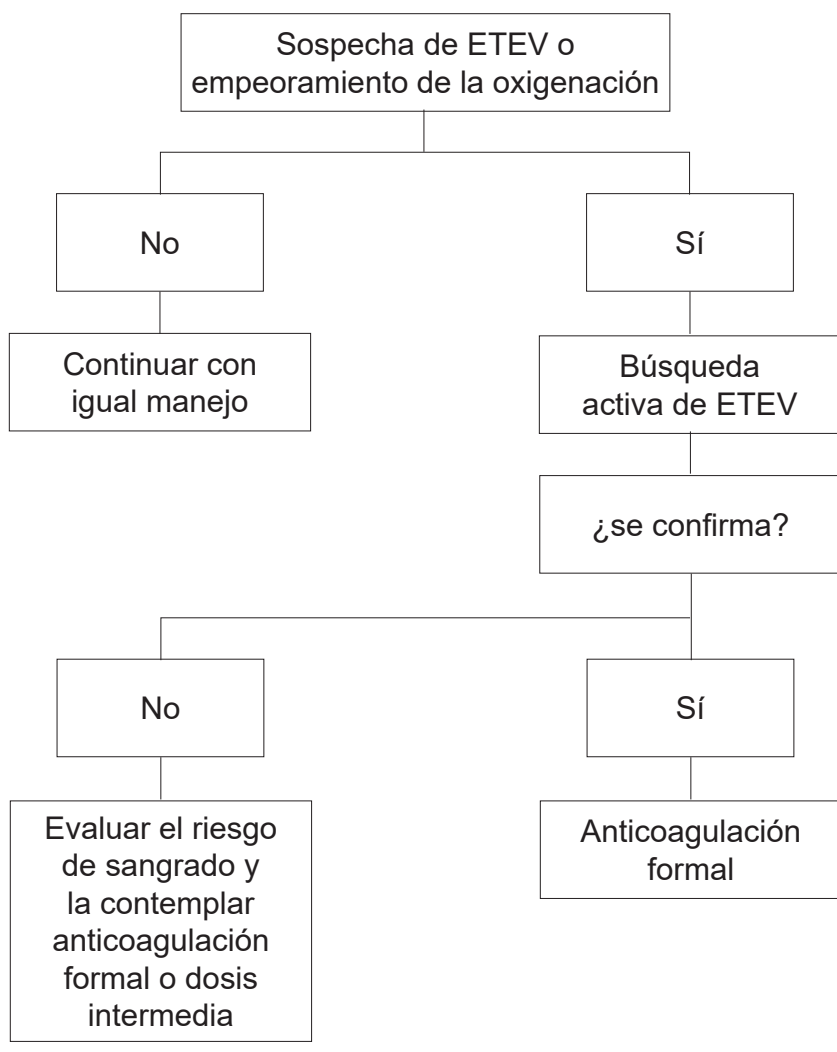

Figura 13. Evaluación de riesgo de ETEV asociada.

\section{Tromboprofilaxis extendida}

Los factores de riesgo de la trombosis en pacientes con enfermedad médica aguda, como la edad mayor de 75 años, cáncer, evento tromboembólico previo, infección aguda o enfermedad respiratoria crónica, conllevan un riesgo aun mayor de presentar eventos tromboembólicos (51). Se ha demostrado que en pacientes con alto riesgo, la mayoría de los eventos ocurre dentro del primer trimestre, después de su salida del hospital, con una tasas entre $6 \%$ y $9 \%$, con 3 o 4 factores de riesgo, respectivamente $(52,53)$.
En la evidencia disponible, la tromboprofilaxis extendida con anticoagulantes directos ha demostrado que el uso de rivaroxabán (estudios MAGELLAN y MARINER) y apixabán (estudio ADOPT) no disminuyen significativamente el riesgo de eventos tromboembólicos, y sí aumentan el riesgo de sangrado. El estudio con betrixabán (estudio APEX) tuvo resultados positivos en cuanto a la reducción de eventos tromboembólicos, sin aumentar el riesgo de sangrado mayor, sin embargo, en el país no se cuenta con este medicamento. En conclusión, se podría realizar profilaxis extendida en pacientes con alto riesgo de trombosis, bajo riesgo de sangrado con enoxaparina de 7 a 14 días (54-58) (Tablas 2 y 3; Figura 13).

Tabla 3. Factores de riesgo de sangrado (59)

\section{Factores de riesgo de sangrado}

- Riesgo de sangrado

- Edad >65 años

- Sangrado previo

- Cáncer

- Falla renal

- Falla hepática

- Trombocitopenia

- ACV previo

- Diabetes

- Anemia

- Tratamiento antiplaquetario

- Comorbilidad y reducción de la capacidad funcional

- Cirugías recientes

- Caídas frecuentes

- Abuso de alcohol

- Uso de AINE

Riesgo estimado

Bajo riesgo: 0 factores de riesgo

Riesgo moderado: 1 factor de riesgo

Riesgo alto: $>2$ factores de riesgo

AINE: antiinflamatorios no esteroideos.

\section{Conclusiones}

El virus SARS-CoV-2 es un coronavirus que, hasta la fecha, no había presentado salto a la especie humana. Es por ello por lo que su expresión como enfermedad (COVID-19) constituye un problema médico grave, potencialmente mortal y sin precedentes, excepto las graves epidemias por SARS-CoV-1 y MERS.

Los mecanismos de transmisión, el tratamiento potencial y su historia natural son aún campos no bien 
definidos, y representan unos de los más grandes retos en la era moderna. La alta infectividad interpersonal, a través de fómites contaminados, ha mostrado ser un factor crítico, que justifica la pandemia actual. La variedad del espectro clínico de presentación y la ausencia de tratamiento específico imponen grandes dificultades diagnósticas y terapéuticas, que se traducen en una sobrecarga y saturación de la oferta actual de los sistemas hospitalarios de salud. Su alta tasa de contagio, su impacto sobre las sociedades, las grandes pérdidas, tanto humanas como económicas, han hecho de esta enfermedad el foco de nuestra atención.

Fisiopatológicamente, el COVID-19 puede tener un compromiso multisistémico muy variado en la gravedad de la presentación. Como se ha descrito, en los pacientes con infecciones severas, el sinergismo de una respuesta inmunitaria innata y la alteración de la hemostasia llevan a los pacientes a desenlaces poco alentadores. De los pacientes que requieren manejo en la unidad de cuidado crítico se ha demostrado una mayor tasa de eventos trombóticos $(6,58)$. La mayoría de estos pacientes se presentan con niveles muy elevados de dímero $\mathrm{D}$, fibrinógeno, modesto descenso de plaquetas y prolongación del TP, así como marcadores más específicos, como la actividad del factor de Von Willebrand, factor VIII y anticoagulante lúpico (58).

Es de resaltar que el comportamiento de esta coagulopatía difiere de la CID asociada con sepsis; en donde, los estudios del uso de anticoagulación con heparina han mostrado un impacto en la mortalidad. Es claro que esta enfermedad se asocia con un estado hipercoagulable y, como tal, deberíamos implementar acciones para la detección temprana y la monitorización frecuente de estos pacientes, ante el alto riesgo de complicaciones tromboembólicas, como la trombosis venosa profunda, el embolismo pulmonar y la trombosis arterial.

Consideramos iniciar dosis mayores de las usuales para el caso de la tromboprofilaxis, como lo recomienda la Sociedad Española de Trombosis y Hemostasia, así como la implementación de anticoagulación formal en pacientes con alto riesgo trombótico, en donde se documente aumento progresivo de los valores de dímero D, empeoramiento clínico, sospecha de una complicación tromboembólica asociada e, inclusive, en casos seleccionados, donde el fenotipo procoagulable del paciente, aun si no se haya podido documentar dicho evento, confiera un alto riesgo de presentar estos eventos, ya que se considera que cuando este se manifiesta significa un estado inflamatorio avanzado, con cambios, en su mayoría irreversibles, que aumentan la mortalidad de estos pacientes.

Hace faltan estudios formales, en donde se pueda evaluar objetivamente esta terapia. Entre tanto, nuestra recomendación es no descartar la anticoagulación como una medida terapéutica en ese subgrupo de pacientes con infección severa con COVID-19, que muestra un fenotipo protrombótico, y en el cual el riesgo de sangrado es bajo o moderado, dependiendo del contexto en el que nos encontremos.

Es muy relevante enfatizar que desconocemos numerosos aspectos fundamentales del virus y la enfermedad en el momento de realizar esta revisión. Por ello, es posible caer en argumentum ad ignorantiam, al igual que otros autores, una falacia de sostener la verdad (o falsedad) de una proposición, alegando que no existe prueba de lo contrario. Muchos de los conceptos aquí descritos son, de hecho, una extensión de lo conocido en otros escenarios o deducciones fisiopatológicas, que no tiene fundamento objetivo en todos los casos. Quienes argumentamos de esta manera en el presente artículo no basamos todos los conceptos en evidencia médica, por ausencia de la misma, pero respondemos a la necesidad de tomar posiciones médicas consensuadas ante el dramático problema del COVID-19. En consecuencia, debemos reconocer y lidiar humildemente con que mucha de la literatura actual referente al COVID-19 se basa en esta falacia de ignorancia. Apelar a que "la ausencia de prueba no es prueba de ausencia" de validez de una propuesta médica, refleja la posición desesperada y obligada, mientras logramos disponer de evidencia científica contrastada y válida. 


\section{Referencias}

1. Guan WJ, Ni ZY, Hu Y, Liang WH, Ou CQ, He JX, et al. Clinical characteristics of coronavirus disease 2019 in China. N Engl J Med. 2020;382:1708-20. doi: 10.1056/NEJMoa2002032.

2. Lu R, Zhao X, Li J, Niu P, Yang B, Wu H, et al. Genomic characterisation and epidemiology of 2019 novel coronavirus: implications for virus origins and receptor binding. Lancet. 2020;395(10224):565-74. doi: 10.1016/S01406736(20)30251-8.

3. European Centre for Disease Prevention and control [Internet]. 2020. COVID-19 pandemic. Disponible en: https://www. ecdc.europa.eu/en/covid-19-pandemic

4. Revista Semana [Internet]. Coronavirus en Colombia hoy 4 de junio: cifra de recuperados sube a 12.921. 2020. Disponible en: https://www.semana.com/casos-coronavirus-colombia-hoy1087-muertos-35120-contagiados-4-de-junio/676304/

5. Cui S, Chen S, Li X, Liu S, Wang F. Prevalence of venous thromboembolism in patients with severe novel coronavirus pneumonia. J Thromb Haemost. 2020;18(6):1421-4. Doi: 10.1111/jth.14830.

6. Middeldorp S, Coppens M, van Haaps TF, Foppen M, Vlaar AP, Müller MCA, et al. Incidence of venous thromboembolism in hospitalized patients with COVID-19. J Thromb Haemost. 2020;18(8):1995-2002. Doi: 10.1111/jth. 14888 .

7. Minet C, Potton L, Bonadona A, Hamidfar-Roy R, Somohano CA, Lugosi M, et al. Venous thromboembolism in the ICU: Main characteristics, diagnosis and thromboprophylaxis. Crit Care. 2015;19(1):1-9. doi: 10.1186/s13054-015-1003-9.

8. Yan Z, Wei C, Meng X, Yuanjie L, Yang Y, Jing Z, et al. Análisis clínico de 7 casos de nueva neumonía grave por coronavirus complicada con isquemia de extremidades. Chinese J Hematol. 2020;(41). Doi: 10.3760/cma.j.issn.0253-2727.2020.0006(5).

9. Oxley TJ, Mocco J, Majidi S, Kellner CP, Shoirah H, Singh IP, et al. Large-vessel stroke as a presenting feature of COVID-19 in the young. N Engl J Med. 2020;382(20):e60. Doi: 10.1056/ NEJMc2009787.

10. Mao L, Jin H, Wang M, Hu Y, Chen S, He Q, et al. Neurologic manifestations of hospitalized patients with coronavirus disease 2019 in Wuhan, China. JAMA Neurol. 2020;77(6):68390. Doi: 10.1001/jamaneurol.2020.1127.

11. Carsana L, Sonzogni A, Nasr A, Rossi RS, Pellegrinelli A, Zerbi $\mathrm{P}$, et al. Pulmonary post-mortem findings in a series of COVID-19 cases from northern Italy: a two-centre descriptive study. Lancet Infect Dis. 2020;20:1135-40. doi: 10.1016/ S1473-3099(20)30434-5.

12. Dolhnikoff M, Duarte-Neto AN, de Almeida Monteiro RA, da Silva LFF, de Oliveira EP, Saldiva PHN, et al. Pathological evidence of pulmonary thrombotic phenomena in severe COVID-19. J Thromb Haemost. 2020;18(6):1517-9. doi: $10.1111 /$ jth.14844.

13. Tang N, Li D, Wang X, Sun Z. Abnormal coagulation parameters are associated with poor prognosis in patients with novel coronavirus pneumonia. J Thromb Haemost. 2020;18(4):8447. doi: $10.1111 /$ jth. 14768 .

14. Levi M, Thachil J, Iba T, Levy JH. Coagulation abnormalities and thrombosis in patients with COVID-19. Lancet Haematol. 2020;7(6):e438-40. doi: 10.1016/S2352-3026(20)30145-9.

15. Lillicrap D. Disseminated intravascular coagulation in patients with 2019-nCoV pneumonia. J Thromb Haemost. 2020;18(4):786-7. doi: 10.1111/jth.14781.

16. Levi M, Scully M. How I treat disseminated intravascular coagulation. Blood. 2018;131(8):845-54. doi: 10.1182/ blood-2017-10-804096.

17. Iba T, Levi M, Levy JH. Sepsis-induced coagulopathy and disseminated intravascular coagulation. Semin Thromb Hemost. 2020;46(1):89-95. doi: 10.1055/s-0039-1694995.

18. Levi M, Toh $\mathrm{CH}$, Thachil J, Watson HG. Guidelines for the diagnosis and management of disseminated intravascular coagulation. Br J Haematol. 2009;145(1):24-33. doi: https://doi. org/10.1111/j.1365-2141.2009.07600.x.

19. Umemura Y, Yamakawa K, Ogura H, Yuhara H, Fujimi S. Efficacy and safety of anticoagulant therapy in three specific populations with sepsis: A meta-analysis of randomized controlled trials. J Thromb Haemost. 2016;14(3):518-30. doi: 10.1111/jth.13230.

20. Taylor FB Jr, Toh CH, Hoots WK, Wada H, Levi M; Scientific Subcommittee on Disseminated Intravascular Coagulation (DIC) of the International Society on Thrombosis and Haemostasis (ISTH). Towards definition, clinical and laboratory criteria, and a scoring system for disseminated intravascular coagulation. Thromb Haemost. 2001;86(5):1327-30.

21. Iba T, Levy JH, Warkentin TE, Thachil J, van der Poll T, Levi $\mathrm{M}$, et al. Diagnosis and management of sepsis-induced coagulopathy and disseminated intravascular coagulation. J Thromb Haemost. 2019;17(11):1989-94. doi: 10.1111/jth.14578.

22. Iba T, Di Nisio M, Levy JH, Kitamura N, Thachil J. New criteria for sepsis-induced coagulopathy (SIC) following the revised sepsis definition: A retrospective analysis of a nationwide survey. BMJ Open. 2017;7(9):1-7. doi: 10.1136/bmjopen-2017-017046.

23. Wrapp D, Wang N, Corbett KS, Goldsmith JA, Hsieh CL, Abiona O, et al. Cryo-EM structure of the 2019-nCoV spike in the prefusion conformation. Science. 2020;367(6483):12603. doi: 10.1126/science.abb2507.

24. Belen-Apak FB, Sarialioglu F. The old but new: Can unfractioned heparin and low molecular weight heparins inhibit proteolytic activation and cellular internalization of SARSCoV2 by inhibition of host cell proteases? Med Hypotheses. 2020;142:109743. doi: 10.1016/j.mehy.2020.109743.

25. Hoffmann M, Kleine-Weber H, Krueger N, Mueller MA, Drosten C, Poehlmann S. The novel coronavirus 2019 (2019-nCoV) uses the SARS-coronavirus receptor ACE2 and the cellular protease TMPRSS2 for entry into target cells. bioRxiv. 2020;2020.01.31.929042. doi: https://doi. org/10.1101/2020.01.31.929042. 
26. Hamming I, Timens W, Bulthuis MLC, Lely AT, Navis GJ, van Goor H. Tissue distribution of ACE2 protein, the functional receptor for SARS coronavirus. A first step in understanding SARS pathogenesis. J Pathol. 2004;203(2):631-7. doi: 10.1002/path.1570.

27. Guo T, Fan Y, Chen M, Wu X, Zhang L, He T, et al. Cardiovascular implications of fatal outcomes of patients with coronavirus disease 2019 (COVID-19). JAMA Cardiol. 2020;5(7):811-8. doi: 10.1001/jamacardio.2020.1017.

28. Vaduganathan M, Vardeny O, Michel T, McMurray JJV, Pfeffer MA, Solomon SD. Renin-angiotensin-aldosterone system inhibitors in patients with Covid-19. N Eng1 J Med. 2020;382(17):1653-9. doi: 10.1056/NEJMsr2005760.

29. Mancia G, Rea F, Ludergnani M, Apolone G, Corrao G. Renin-angiotensin-aldosterone system blockers and the risk of Covid-19. N Engl J Med. 2020;382(25):2431-40. doi: 10.1056/NEJMoa2006923.

30. Thachil J. The versatile heparin in COVID-19. J Thromb Haemost. 2020;18(5):1020-2. doi: 10.1111/jth.14821.

31. Huang C, Wang Y, Li X, Ren L, Zhao J, Hu Y, et al. Clinical features of patients infected with 2019 novel coronavirus in Wuhan, China. Lancet. 2020;395(10223):497-506. doi: 10.1016/S0140-6736(20)30183-5.

32. Varga Z, Flammer AJ, Steiger P, Haberecker M, Andermatt $\mathrm{R}$, Zinkernagel AS, et al. Endothelial cell infection and endothelitis in COVID-19. Lancet. 2020;395(10234):1417-8. doi: 10.1016/S0140- 6736(20)30937-5.

33. Shi Y, Wang Y, Shao C, Huang J, Gan J, Huang X, et al. COVID-19 infection: the perspectives on immune responses. Cell Death Differ. 2020;27(5):1451-4. doi: 10.1038/s41418-020-0530-3.

34. McGonagle D, O’Donnell J, Sharif K, Emery P, Bridgewood C. Immune mechanisms of pulmonary intravascular coagulopathy (PIC) in COVID-19 pneumonia. Lancet Rheumatol. 2020;2019(20):1-9. doi: 10.1016/S2665-9913(20)30121-1.

35. Gupta N, Zhao YY, Evans CE. The stimulation of thrombosis by hypoxia. Thromb Res. 2019;181:77-83. doi: 10.1016/j. thromres.2019.07.013.

36. Zhou F, Yu T, Du R, Fan G, Liu Y, Liu Z, et al. Clinical course and risk factors for mortality of adult inpatients with COVID-19 in Wuhan, China: a retrospective cohort study. Lancet. 2020;395(10229):1054-62. doi: 10.1016/S01406736(20)30566-3.

37. Adam SS, Key NS, Greenberg CS. D-dimer antigen: Current concepts and future prospects. Blood. 2009;113(13):2878-87. doi: 10.1182/blood-2008-06-165845.

38. Harper PL, Theakston E, Ahmed J, Ockelford P. D-dimer concentration increases with age reducing the clinical value of the D-dimer assay in the elderly. Intern Med J. 2007;37(9):60713. doi: 10.1111/j.1445-5994.2007.01388.x.

39. Stein PD, Hull RD, Patel KC, Olson RE, Ghali WA, Brant R, et al. D-dimer for the exclusion of acute venous thrombosis and pulmonary embolism. Ann Intern Med. 2004;140(8):589607. doi: 10.7326/0003-4819-140-8-200404200-00005.

40. Trapani LM. Thromboelastography: Current applications, future directions. Open J Anesthesiol. 2013;03(01):23-7. doi: http://dx.doi.org/10.4236/ojanes.2013.31007.

41. Bolliger D, Seeberger MD, Tanaka KA. Principles and practice of thromboelastography in clinical coagulation management and transfusion practice. Transfus Med Rev. 2012;26(1):1-13. doi: 10.1016/j.tmrv.2011.07.005.

42. Panigada M, Bottino N, Tagliabue P, Grasselli G, Novembrino C, Chantarangkul V, et al. Hypercoagulability of COVID-19 patients in Intensive Care Unit. A report of thromboelastography findings and other parameters of hemostasis. J Thromb Haemost. 2020;18(7):1738-42. doi: 10.1111/jth.14850.

43. Thachil J, Tang N, Gando S, Falanga A, Cattaneo M, Levi $\mathrm{M}$, et al. ISTH interim guidance on recognition and management of coagulopathy in COVID-19. J Thromb Haemost. 2020;18(5):1023-6. doi: https://doi.org/10.1111/jth.14810.

44. Samama MM, Cohen AT, Darmon JY, Desjardins L, Eldor A, Janbon C, et al. A comparison of enoxaparin with placebo for the prevention of venous thromboembolism in acutely ill medical patients. N Engl J Med. 1999;341(11):793-800. doi: 10.1056/NEJM199909093411103.

45. Tang N, Bai H, Chen X, Gong J, Li D, Sun Z. Anticoagulant treatment is associated with decreased mortality in severe coronavirus disease 2019 patients with coagulopathy. J Thromb Haemost. 2020;18(5):1094-9. doi: 10.1111/jth.14817.

46. Bompard F, Monnier H, Saab I, Tordjman M, Abdoul H, Fournier L, et al. Pulmonary embolism in patients with Covid-19 pneumonia. Eur Respir J. 2020;57(1). doi: 10.1183/13993003.01365-2020.

47. Kreuziger LB, Lee A, Garcia D, Cuker A, Cushman M, DeSancho M, et al. COVID-19 and VTE/anticoagulation: frequently asked questions. 2020. Disponible en: https://www. hematology.org/covid-19/covid-19-and-vte-anticoagulation

48. Song JC, Wang G, Zhang W, Zhang Y, Li WQ, Zhou Z, et al. Chinese expert consensus on diagnosis and treatment of coagulation dysfunction in COVID-19. Mil Med Res. 2020;7(1):19. doi: 10.1186/s40779-020-00247-7.

49. Testa S, Paoletti O, Giorgi-Pierfranceschi M, Pan A. Switch from oral anticoagulants to parenteral heparin in SARS-CoV-2 hospitalized patients. Intern Emerg Med. 2020;(0123456789):3-5. doi: 10.1007/s11739-020-02331-1.

50. Sociedad Española de Trombosis y Hemostasia [Internet]. Recomendaciones de tromboprofilaxis y tratamiento antitrombótico en pacientes. 2020. Disponible en: https://www.covid-19. seth.es/recomendaciones-de-tromboprofilaxis-y-tratamientoantitrombotico-en-pacientes-con-covid-19/

51. Alikhan R, Cohen AT, Combe S, Samama MM, Desjardins L, Eldor A, et al. Risk factors for venous thromboembolism in hospitalized patients with acute medical illness: Analysis of 
the MEDENOX Study. Arch Intern Med. 2004;164(9):963-8. doi: 10.1001/archinte.164.9.963.

52. Hull RD, Merali T, Mills A, Stevenson AL, Liang J. Venous thromboembolism in elderly high- risk medical patients: Time course of events and influence of risk factors. Clin Appl Thromb. 2013;19(4):357-62. doi: 10.1177/1076029613481105.

53. Spencer FA, Lessard D, Emery C, Reed G, Goldberg RJ. Venous thromboembolism in the outpatient setting. Arch Intern Med. 2007;167(14):1471-5. doi: 10.1001/archinte.167.14.1471.

54. Dalen JE, Stein PD, Plitt JL, Jaswal N, Alpert JS. Extended thromboprophylaxis for medical patients. Am J Med. 2020;133(1):9-11. doi: 10.1016/j.amjmed.2019.05.050.

55. Cohen AT, Spiro TE, Büller HR, Haskell L, Hu D, Hull R, et al. Rivaroxaban for thromboprophylaxis in acutely ill medical patients. N Engl J Med. 2013;368(6):513-23. doi: 10.1056/ NEJMoa1111096.
56. Spyropoulos AC, Ageno W, Albers GW, Elliott CG, Halperin JL, Hiatt WR, et al. Rivaroxaban for thromboprophylaxis after hospitalization for medical illness. N Engl J Med. 2018;379(12):1118-27. doi: 10.1056/NEJMoa1805090.

57. Bikdeli B, Madhavan MV, Jimenez D, Chuich T, Dreyfus I, Driggin E, et al. COVID-19 and thrombotic or thromboembolic disease: implications for prevention, antithrombotic therapy, and follow-up. J Am Coll Cardiol. 2020;75(23):2950-73. doi: 10.1016/j.jacc.2020.04.031.

58. Helms J, Tacquard C, Severac F, Leonard-Lorant I, Ohana M, Delabranche X, et al. High risk of thrombosis in patients in severe SARS-CoV-2 infection: a multicenter prospective cohort study. Intensive Care Med. 2020:1-10. doi: 10.1007/ s00134-020-06062-x.

59. Kearon C, Akl EA, Ornelas J, Blaivas A, Jimenez D, Bounameaux $\mathrm{H}$, et al. Antithrombotic therapy for VTE disease: CHEST guideline and expert panel report. Chest. 2016;149(2):315-52. doi: 10.1016/j.chest.2015.11.026. 